\title{
A Case of Schizotypal Personality Disorder
}

\author{
Navneet Bidani ${ }^{1}$ \\ ${ }^{1}$ Dr. Bidani's Centre for Homoeopathy, Hisar, Haryana, India \\ Homœopathic Links 2017;30(2):139-143.
}

\begin{abstract}
Address for correspondence Dr. Navneet Bidani, Dr. Bidani's Centre for Homoeopathy, 12-N, Model Town, Hisar-125001, Haryana, India (e-mail: drbidani@gmail.com).
\end{abstract}

\author{
Abstract \\ Keywords \\ - Personality disorders \\ - Cluster A personality \\ disorder \\ - Schizotypal \\ personality disorder \\ - Delusions \\ - Formication \\ - Zincum metallicum
}

Personality disorders are a group of conditions characterised by an inability to get on with other people and learn from experience. People with a personality disorder may find that their beliefs and attitudes are different from those of most other people. Others may find their behaviour unusual, unexpected or perhaps offensive. In this article, we discuss a case of a 42-year-old man with schizotypal personality disorder with typical delusions of being abused and persecuted and subsequent formication. With a properly selected homeopathic medicine, the patient experienced symptom improvement in self-confidence, somatic complaints, stress and worry, anxiety and delusions, suggesting that homeopathy is quite useful in the treatment of such personality disorders.

\section{Introduction}

The 10 different personality disorders can be grouped into three clusters based on descriptive similarities within each cluster. These clusters are:

- Cluster A (the 'odd, eccentric' cluster).

- Cluster B (the 'dramatic, emotional, erratic' cluster).

- Cluster C (the 'anxious, fearful' cluster).

Cluster A is called the odd, eccentric cluster. It includes paranoid personality disorder, schizoid personality disorder and schizotypal personality disorders. The common features of the personality disorders in this cluster are social awkwardness and social withdrawal. These disorders are dominated by distorted thinking. ${ }^{1}$

People with schizotypal personality disorder are typically socially isolated, like those with schizoid personality disorder. In addition, however, they also behave in ways that would seem unusual to many of us, and they tend to be suspicious and to have odd beliefs. People given a diagnosis of schizotypal personality disorder are often considered 'odd' or 'bizarre' because of how they relate to other people, how they think and behave, and even how they dress. They have ideas of reference, which means they think insignificant events relate directly to them. ${ }^{2}$

Further research on the treatment of people with this disorder is important for a variety of reasons. They tend not to improve over time, and some evidence indicates that some will go on to develop the more severe characteristics of schizophrenia. $^{3}$

\section{Case}

Raghav (not his real name) was born and raised in Hisar, Haryana. His father, who died when Raghav was 18 , was a janitor at a local department store. His mother was a homemaker. Neither of his parents finished high school, and Raghav was born when they were only 17 years old. Raghav is 42 years old and has been working as a driver for a postal company for the past 15 years. He reports that for few months he is feeling a crawling sensation under his skin that is temporarily relieved by scratching. The sensation is so intense that he even gets up from sleep at night to scratch.

Appearance: Petite man. Looks drawn and tired, sits with his arms folded across his body.

Raghav is an only child, and he explains that he got a lot of attention. He says that he loved his parents very much, 'but they were kind of weird'. He adds that 'They were like me. Just different, you know'.

Raghav has been unmarried his entire life. He reports 'I liked the girls OK and all that' but he never developed permanent relationships. Raghav reports that he has always been 'nervous with the girls and such' and he avoids making any significant social overtures with women. He meets his 
sexual needs in a matter-of-fact way by visiting a prostitute on a regular basis. He reports that their sexual encounters are highly regimented. He refuses to elaborate on this point, stating that his mother taught him to 'never talk about dirty things'.

Raghav reports that he also directed a lot of his energy into long walks. Every evening, he would go for a walk, sometimes lasting up to 5 hours. His neighbours were often concerned seeing him walking alone late at night and the police have been called on several occasions. Recently, however, Raghav has lost interest in the walks, explaining that the streets are too dangerous. Raghav has visited temple on a regular basis throughout his life. He has been involved in several community activities; people seem to appreciate his involvement, though they find him a bit odd.

During the past 2 years, co-workers have noticed a gradual change in Raghav. While he always seemed a bit unusual, during the past few years, his social interactions seem confused and inappropriate. He sometimes smiles when he is angry, and often seems distressed and agitated when everyone else is laughing. A co-worker who befriended him reports that Raghav may be using hallucinogenic drugs. Raghav denies this, however.

Although co-workers have described a gradual decline, one dramatic event seems to have exacerbated his condition. Raghav was scheduled to make a routine delivery, but instead of taking the box into the store, he handed it to a pedestrian who happened to be on the street. As he handed it to her, he explained 'This is a gift from God-please keep it with you always'. The puzzled pedestrian reported the incident to Raghav's supervisor. The following day, Raghav was unable to clearly recall the incident, and had no explanation for it. Although his actions were highly unusual, it was an isolated incident and his supervisor let him off with a warning. Unfortunately, the error became known around the station, and co-workers teased him for several weeks. Raghav explains that this error weakened his low self-image, and undercut his confidence in his ability to perform his job. Ever since this event, Raghav has become very careful to avoid making mistakes. He routinely doublechecks all of his deliveries, sometimes running back into stores to confirm that he has delivered the correct box. He admitted that he sometimes hears celebrity voices warning him in abusive and filthy language that he is making an error.

Raghav spends his spare time in solitary behaviours, including watching television (he watches a lot of Court TV) and building plastic military models. During the past 6 months, Raghav also admits to carefully checking all of the locks on his house at night. Although Raghav lives in a comfortable neighbourhood, he points out that all of the young people in the area dislike him and they may be planning to break into his house. He also disconnects his phone at night to avoid potential threatening phone calls.

Finally, Raghav has recently begun insisting that he is suffering from cirrhosis of the liver. Although medical tests have proven negative, he insists that he can feel the organ rotting inside of him. This thought seems to have developed after he watched a television program on the side effects of alcoholism.

Q: Can you please elaborate the crawling sensation? Is it just an itching or something else?

'Doctor, it is not an itching, it's just that something is moving inside my skin. It can occur anywhere and at any time, then I'll have to either rub it or scratch it, which gives a temporary relief. I tried my best to observe if it increases with any food item or in any season but couldn't notice anything'.

\section{Q: Is there any significant past history of any illness?}

'Nothing much, just a seasonal cold and cough. And few years back, I was having severe fungal infection under my armpits and in groins. The itching was so intense at that time, especially at night that I used to scratch until it bleeds. Then I consulted a dermatologist, who prescribed me antifungal ointments to be applied every four hours. The infection was so severe that I'll have to apply those ointments for more than a month'.

Q: Raghav, what happened on the day when you made a mistake and delivered the package to a person on the street?

'I don't remember it so good. It's like it was another time. Anyway, I know I was doing my regular work, running from place to place. I remember that I was really tired; I did my thing with my girlfriend real late the night before, and I was really tired. So I was working when one of the boxes started talking to me in a filthy language. They do that, sometimes. All of the drivers know it'.

Q: Raghav, you used to enjoy taking walks. Why did you stop doing this?

'I think it is too dangerous. This neighbourhood aren't what it used to be. Even the shopping mall. The kids that sit there are dangerous. And they especially don't like people like me. They know about me, and they don't like it. Maybe they are just jealous. They know I am older than them, and that they have to listen to what I say. So they don't like me and they try to think of ways that they can hurt me. Once, when I came out of the grocery store, a bunch of kids had pushed a shopping cart into my car. I'm just lucky I wasn't around when they did it'.

\section{Q: Do you drink much alcohol?}

'Yeah, but not that much. That stuff rots your guts. I can already feel it doing that to me. But I only have one beer a week. It's my limit. But now, I'm stopping even that. Man, I can just feel my liver rotting. It is the strangest damn thing. It is like I can see into my body, and it is so ugly. The doctors can't see it with their machines. But I can. I know what's going on inside my body'. 


\section{Q: What is your favourite television program?}

'I like watching TV. Sometimes it's the only person I have to talk to. It's the only person who isn't judging me. I really like watching the animal shows. I think it is really something the way these animals get around and do things. I could never do that many things because I'm too busy. I mean once, I ran all the way to the store to buy some bread and the store was closed. They shouldn't close on weekends so damn early. So I took a bath. (See, how he is jumping from one topic to another).

\section{Q: Please tell me about your childhood.}

'I grew up mostly normal, I think. I was their only kid, and Momma and Daddy; was real nice; they never pushed me to do anything. They tell me I was in diaper till I was more than four years old, but they didn't worry about it none. We were poor, and we usually didn't eat real well. But when daddy was working things were good. Daddy had problems keeping a job. People didn't like him. Like I told you, my parents were kind of funny, like me. They didn't have many friends, really, and Daddy had trouble with his bosses. Most nights we'd just sit at home, sort of talking or watching TV. Daddy and Momma, they got along pretty good. The only time they'd fight was when Daddy went away on his business trips. He'd be away for two, three days. A week sometimes. That was the only time I ever saw them fight, when he come back from his trips'.

\section{Q: Raghav, do you think you have a problem?}

'I don't know. I talked with my girl about it. She told me that she didn't want to visit me at a mental hospital, and so I told her she didn't have to. I mean, there isn't any reason why she should drive her car so much. Man, cars are really expensive and she doesn't have a lot of money. I know that money shouldn't be all that important, but it really is. If you don't have money, you don't have shit. (Once again, notice how he is shifting from one topic to another).
Family history: Maternal grandmother died in her 50s from TB. Father had rheumatic and muscular complaints. Alcoholic.

There was nothing peculiar or important in his personal history, apart from his strong aversion to fish and his disturbed sleep due to overcrowding of thoughts.

I chose the following rubrics ( - Fig. 1), and the remedy that comes through these rubrics is Zincum metallicum (-Fig. 2).

Plan: Zincum metallicum 1M, single dose.

\section{Follow-up}

After taking one dose of the remedy my patient said, nothing happened. Everything is same as before. Still I feel that crawling sensation beneath my skin. Nothing has changed at all.

Plan: Wait.

\section{Follow-up after 40 Days}

'Overall, I feel better. Crawling sensation is less; I now feel it only at bedtime. My mind is calmer. I have come back. I went through some erratic stuff a while ago. It didn't feel okay for me to be so way out and weird. It was a hallucination based on my emotions not working or on negative emotions. I was doing things that were abnormal during the three-week period when things went haywire just before I came to see you. I felt some bodily discomfort, which lasted until recently, such as sore muscles, twitching, and various sensations running through my body. Before I took the remedy I had communications in the back of my head. I heard voices. This has stopped now. One voice bothered me. It was a very critical voice that exposed my family or said things that were not true, sexual things. I am still restless at night, but now I go for a strong walk and come home and fall asleep'.

Assessment: His conscience is back under control. He is not expanding into the universe anymore. The remedy is correct.

Plan: Wait.

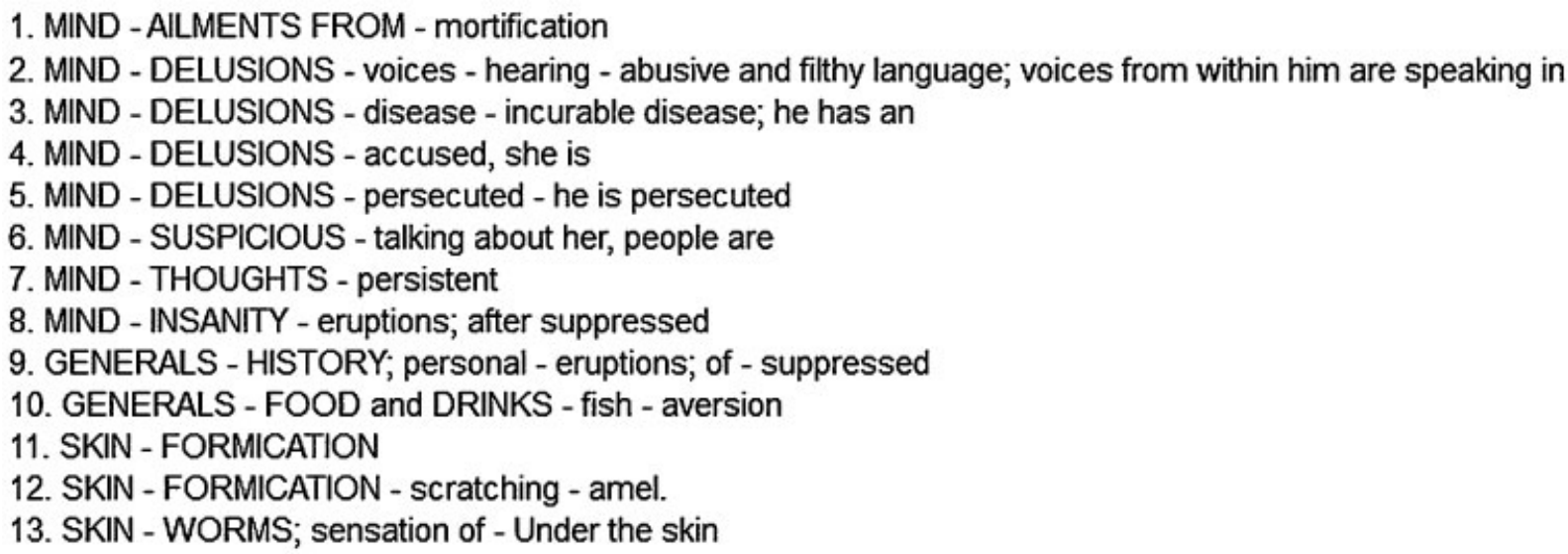

Fig. 1 Selected rubrics (Synthesis 9.0 Repertory by Schroyens F.). 


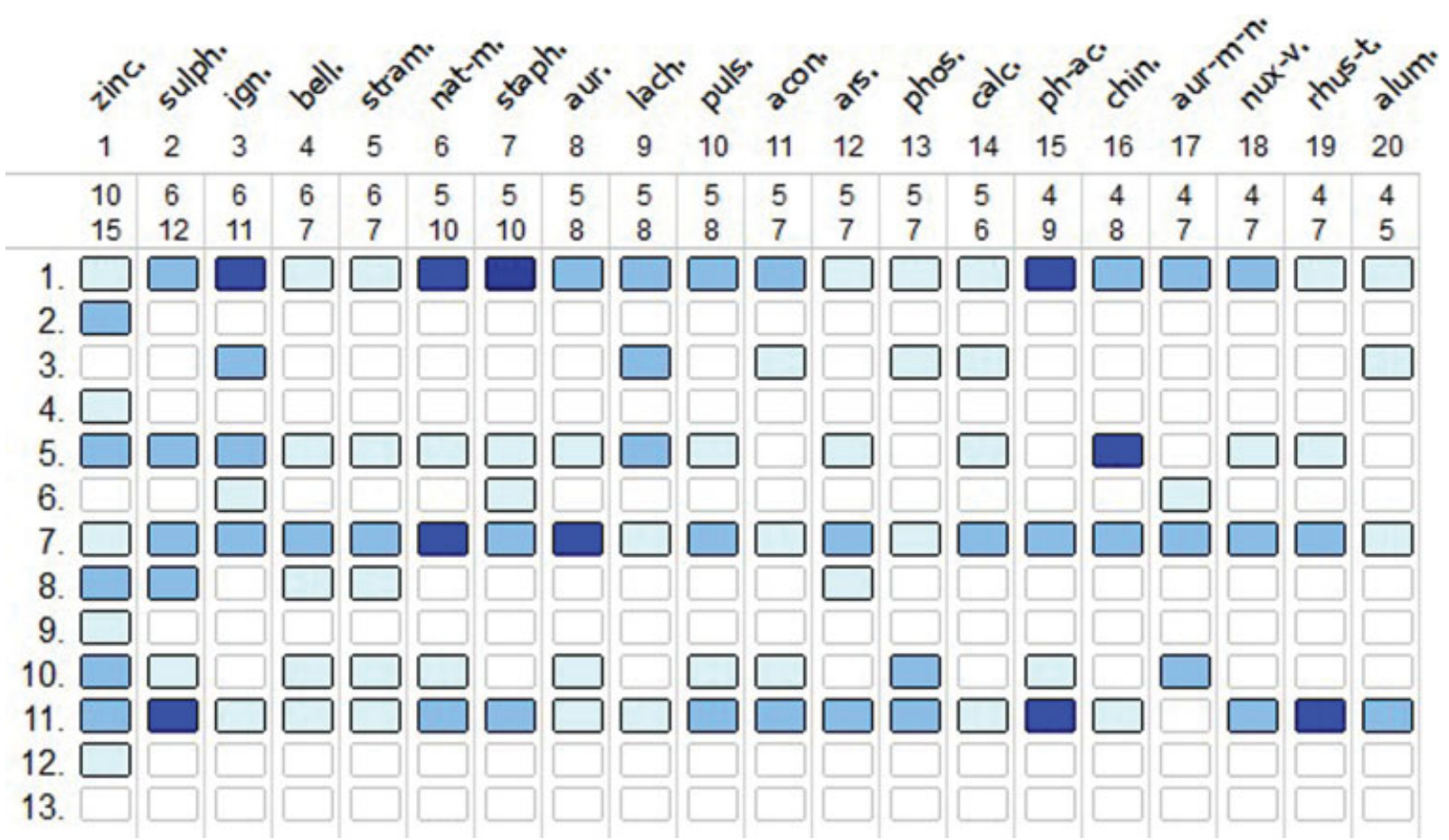

Fig. 2 Repertorisation (RADAR 10.5 .003 software).

\section{Six Months after the Remedy}

'Behaviour is going into the pit. Started dropping things at work and switching the lights on and off. I'm pulling inward, away from the "world." Somehow retreating. Restless. Can't sit still. Rocking back and forth. Unaware, until my girlfriend told me. Can't go to work. Just arrange and rearrange the same shelf. Can't stop. It feels incomplete and not together. Can't seem to get it all together. Feel lost inside. Not sleeping. Wandering at night. Finding places to sit and look into the darkness'.

Assessment: I could not find the cause of this relapse or anything else that might have interfered. It would be a good test for the remedy, to see if a repetition would keep the case moving forward.

Plan: Zincum metallicum 1M, single dose.

\section{After Second Dose}

'After the remedy I slept for two days. Back at work. Able to work. Feeling shaky still. I think things are better now. But again I got a fungal infection under my armpits'. (Hering's Law)

Plan: Wait.

\section{Long-Term Follow-up}

I saw this man several more times. He continued to be well. There is no crawling sensation beneath the skin. The symptoms of sleeplessness were much better. No more fungal (tinea) infection is there; it got resolved by its own within few days. He is not walking the streets at night. No medica- tion has been needed. His ability to be with people and interact continued to improve. The patient recovered and has remained well for the past 2 years.

\section{Conclusion}

With this case, we have learnt that the homeopathic understanding of health is closely connected to understanding the mind. Homeopathic approach catalyses a healing process that will raise the person's overall level of health by reaching a state of balance mentally and physically. Constitutional treatment is an innovative healing modality, which helps eliminate behavioural negativities by taking into account your overall nature, personality traits and attitude toward life. These remedies act on mind tapping one's natural ability to release negative emotions and restore well-being that was previously within. With a properly selected homeopathic medicine, as in the above case, the patient experiences symptom improvement in self-confidence, somatic complaints, stress and worry, anxiety and depression, suggesting that homeopathy is quite useful in the treatment of such personality disorders. The case also shows that the suppression of eruptions especially endangers mentally vulnerable patients. Zincum is one of the remedies to be considered if, after suppressed eruptions, neurological or psychiatric symptoms arise.

\section{References}

1 Hoermann S, Zupanick CE, Dombeck M. MentalHelp.net 2015. DSM-5: The Ten Personality Disorders: Cluster A. Available at: 
https://www.mentalhelp.net/articles/dsm-5-the-ten-personality-disorders-cluster-a/; Accessed February 8, 2016

2 Vincent Mark Durand, David Harrison Barlow: Essentials of Abnormal Psychology, 6th ed. Independence, KY: Cengage Learning; 2010
3 Parnas J, Raballo A, Handest P, Jansson L, Vollmer-Larsen A, Saebye $D$. Self-experience in the early phases of schizophrenia: 5 -year follow-up of the Copenhagen Prodromal Study. World Psychiatry 2011;10(03):200-204 